Pero esto no es todo, y desde luego no es lo más importante. Lo que personalmente me parece más destacable es la calidad estética del documental en sí. Las imágenes, secuencias, ritmos, sonidos -además de la voz del narrador y de algunos de los maestros, el documental tiene una preciosa banda sonora de música de instrumentos tradicionales- son de una calidad extraordinaria, resultado de un proceso de producción muy profesional. Sólo por este motivo, por ver algunos de los emplazamientos más bellos donde se desarrollan las artes marciales, y por ver las actuaciones de los monjes Shaolín, de los maestros de tai-chi, wu-shu, kyudo, kendo, kárate o aikido, merece la pena sentarse a ver este DVD.

En definitiva, The empty mind. The Spirit and Philosophy of Martial Arts es un producto para el consumo masivo, pero un producto de consumo masivo de una gran calidad. Cualquiera de las cadenas de televisión actuales -obviamente aquellas preocupadas por dotar de un cierto nivel cultural a sus contenidos- no tendría problema en emitir este documental, pudiendo tener como espectadores, al mismo tiempo, a personas que apenas saben nada de las artes marciales, a principiantes y a profesores o maestros. Y, posiblemente, todos disfrutarían de este hermoso documental.

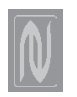

\section{Mind Over Muscle: Writings From the Founder of Judo}

Por Jigoro Kano

Tokyo: Kodansha Internacional, 2006

160 páginas. $12,7 \times 19 \mathrm{~cm}$.

I.S.B.N.: 47-7003-015-0 • \$19.95

Idioma: Inglés

Disponible en:

Kodansha International Inc. c/o Oxford University Press

2001 Evans Road

Cary, NC 27513

Telf: + 1800.451 .7556

Fax: +1 991.677.1303

www.thejapanpage.com

\section{Revisión por Damon Young}

Para muchas personas, las palabras “artes marciales japonesas” evocan imá- genes de monjes voladores, chorros de sangre y dientes rotos, o gamberros musculosos con puños callosos. Aunque sean muy populares en Occidente, las artes marciales japonesas evocan frecuentemente miedo, mistificación o simplemente un grito "¡whoohaaaah!” a lo Bruce Lee. Ciertamente, las artes marciales han atraído un gran número de artistas, gamberros y comediantes decididos a obtener un rápido reconocimiento o remuneración.

Sin embargo no todas las artes marciales tratan de esto. La reciente publicación de los escritos del Dr. Jigoro Kano, Mind Over Muscle: Writings From the Founder of Judo, es un ejemplo de estas ideas. En este libro bellamente encuadernado, de pastas duras, publicado por Kodansha, se desarrollan las ideas del fundador del judo en tres sencillos capítulos: "El desarrollo del judo", "El espíritu del judo", y "Entrenamiento del judo". Aunque no esté ilustrado, como el Kodokan Judo del mismo Kano, este breve libro ofrece una visión mucho mejor de su visión del judo. Como su contemporáneo Funakoshi Gichin, el fundador del kárate moderno, Kano veía el judo como mucho más que un modo de magullar, romper y estrangular a un enemigo. En vez de ello, concebía el judo como un modo de desarrollo físico, intelectual y moral. Mientras que muchas escuelas de artes marciales hablan de estas cosas, lo que define a esta colección de escritos es la claridad y simplicidad con la que están orientados, con cada capítulo estructurado en sucintas subsecciones y repleto de anécdotas clarificantes. Por supuesto esto no es una coincidencia, tal y como señala el epílogo de Murata Naoki, ya que Kano era el director de la primera Escuela Normal de profesores de Japón. En otras palabras, era un educador. Esto significa no sólo que sus escritos son educativos en eficacia y efectividad, sino que también el judo mismo fue desarrollado como un método educativo para viejos y jóvenes, hombres y mujeres, japoneses y no japoneses. Ciertamente, una de las razones por las que los escritos de Kano siguen siendo importantes para las audiencias contemporáneas es que fueron elaborados para combatir vicios como la pereza y el egoísmo, las pesadillas de las genera- ciones criadas en las políticas neoliberales, videojuegos y la televisión de los "reality".

Por tanto, ¿cómo llega el judo a los "emprendedores" de este camino de "desinterés"? En Mind Over Muscle el principio esencial de Kano es traducido por Nancy H. Ross como "el mejor uso de la energía”. Por ejemplo, durante la práctica del judo los estudiantes se enfrentan a menudo con oponentes más grandes y fuertes. En vez de enfrentar fuerza contra fuerza, el mejor uso de su energía es usar la fuerza de su oponente contra él, de tal modo que este se vea en un compromiso, sea desequilibrado, etc. Cuando se golpea o se rompe una inmovilización la fuerza puede ser un valor. La idea no es usar la fuerza todo el tiempo o la suavidad todo el tiempo, sino hacer el mejor uso de lo que tengamos: el mejor uso de la propia energía, o simplemente "máxima eficiencia". Este principio de "máxima eficiencia" puede ser aplicado a la vida cotidiana, que significa no gastar energía en quejarse o encolerizarse. Significa no desperdiciar tiempo y energía en sentirse frustrado, enfadado o dolido. Si tenemos metas claras hemos de usar la energía para lograrlas paciente pero decisivamente, sin malgastarlas en diversiones inútiles o gratificaciones a corto plazo. En conclusión, significa fijar la mirada en nuestro destino y en el camino que nos llevará allí.

Para Kano es en este "caminar el camino" para lo que el judo es especialmente útil. Para aquellos que nunca hayan visto judo esta práctica involucra fundamentalmente a hombres adultos proyectándose uno al otro, luchando y generalmente sudando todo el tiempo en una danza mano a mano habitualmente elegante -aunque a veces no-. En el combate, argumenta Kano, los estudiantes desarrollan algunas habilidades esenciales: observación, memoria, experimentación, imaginación, lenguaje y amplitud de mente. La observación es necesaria para aprender, y la memoria es importante para retener lo que se aprende. Le experimentación es esencial para aprender nuevas técnicas en situaciones variadas, y la imaginación ayuda a los estudiantes a desarrollar nuevas técnicas o a visualizarlas en situaciones 
alternativas. El lenguaje se requiere para explicar las técnicas a los estudiantes y a los compañeros, que necesitan amplitud de mente para aceptar las nuevas técnicas, estilos, aplicaciones, etc. Ciertamente, los estudiantes verán con el tiempo la belleza en estas técnicas. Sobre todo esto, los estudiantes aprenderán también a cooperar por un beneficio mutuo y desarrollarán virtudes tales como el coraje, honestidad, ecuanimidad y generosidad. Estas virtudes no serán puramente intelectuales, pero casan bien con la actividad física. La idea de Kano es que estas habilidades y virtudes no son útiles únicamente en la sala de entrenamiento, sino que también funcionan en el día a día. Efectivamente, Kano cree que el combate sólo es el primer nivel del judo. El segundo nivel es un cuerpo y una mente sana, y el tercer nivel es la contribución a la sociedad, para lo que son esenciales un cuerpo y mente robustos. Así, el judo fue diseñado para darnos salud corporal, agudeza mental y hábitos virtuosos para ayudar al desarrollo de nuestras sociedades.

Por supuesto, como muchas otras artes marciales japonesas, el judo se ha transformado en deporte, y en un deporte Olímpico. Mientras que esto produce excelentes atletas e inspira a generaciones de estudiantes por todo el mundo, también tiene una influencia corruptora. Para Kano esto se debe a que entrenar para ganar compromete el espíritu de amplitud de mente en la enseñanza y en el aprendizaje -los estudiantes entrenan "la" técnica letal, "la" táctica ganadora, etc.-. Esto lleva a la estrechez y al empecinamiento, mientras que el judo debe dirigirse hacia la amplitud de mente y a la flexibilidad. Asimismo, puede producir obsesión con la fama y la riqueza, que nuca deberían ser perseguidas como fin en sí mismas. Los atletas mejor pagados de hoy seguramente tienen conciencia de estos riesgos, así como de los dudosos rasgos personales que los acompañan -hemos oído muchas historias de riñas, ingratitud, de hombres y mujeres deportistas de mal carácter como para pensar lo contrario [de lo positivo del deporte]-. Las razones de Kano para creer que el auténtico judo está por encima de las trampas del deporte y la comercialización era que era un cami- no de vida, y no simplemente un juego. En sus palabras, "el judo no es simplemente un arte marcial sino más bien el principio básico del comportamiento humano" (p. 77). Este principio de "mejor uso de la propia energía", junto con la otra máxima fundacional del judo, "beneficio mutuo", es lo que le coloca lejos de muchos otros deportes y de muchas de las artes marciales ultra violentas. En este sentido, Mind Over Muscle no es solamente una excelente fuente de información sobre una de las mayores historias de éxito del s. XX, sino que también se proyecta como una guía educativa para la vida.

Desde luego, también hay defectos. Como resultado de las muchas conferencias y publicaciones de Kano, Mind Over Muscle es muy repetitivo. A pesar de la claridad y simplicidad de su escritura -y de la sensata traducción de Ross-, el libro podría haber sido un poco más breve, quizá para dejar espacio a otros escritos, ilustraciones o fotografías. Asimismo, algunas de los comentarios positivos de Kano parecen muy pasados de moda, por ejemplo su indulgente aprobación de los principios de eficiencia detrás del Taylorismo en los Estados Unidos parecen alegremente despreocupados de los peligros que esta forma de organización plantearía globalmente. En una visión retrospectiva, la "eficiencia" de Taylor es absolutamente antiética al espíritu del judo. Algunas de las anécdotas de Kano -por ejemplo sobre Moshe Feldenkrais o el luchador Americano Dalue- parecen particularmente condescendientes, quizá como resultado de la aproximación pedagógica de Kano a las cosas. Finalmente, está el problema común a todos los libros de artes marciales: al final del día lo haces o no lo haces. No hay cantidad de lectura que pueda reemplazar el entrenamiento real y su aplicación realista.

Si bien, en conjunto, esta es una excelente introducción a las ideas en las que se basa el judo y a las contribuciones positivas que las artes marciales como el judo pueden hacer a los individuos y a las sociedades. Representa los genuinos intentos de Kano para casar las artes de combate con la educación física, y con un ethos de cooperación, altruismo y desarrollo personal. Para cualquier persona interesada en leer sobre estos asuntos, o simplemente sobre el origen de una de las primeras artes marciales de Japón, Mind Over Muscle es un excelente título para su biblioteca particular.

\section{Chinese Martial Arts Training Manuals: A Historical Survey}

Por Brian Kennedy and Elizabeth Guo Berkeley, CA: North Atlantic Books, 2005

328 páginas. $15,2 \times 20,3 \mathrm{~cm}$.

Ilustraciones

I.S.B.N.: $1-55643-557-6 \bullet \$ 19.95$

Idioma: Inglés.

Disponible en:

North Atlantic Books/Frog, Ltd.

P.O. Box 12327

Berkeley, CA 94712

Telf.: +1 800.337.2665

Fax: +1 510.559.8279

Email:orders@northatlanticbooks.com www.northatlanticbooks.com

\section{Revision por Nyle C. Monday}

No es habitual que buscador casual en la sección de artes marciales de una librería se encuentre con algo verdaderamente único. Mientras que algunos autores han sido capaces de romper con el formato de libros de "como hacer", la gran mayoría de obras publicadas todavía se ocupan de los aspectos técnicos de uno u otro estilo. Sin duda, la razón de esto es la gran demanda de este tipo de libros. Esto hace que sea un placer aún mayor cuando algo diferente a lo habitual aparece en la estantería, ofreciendo llevar al lector en un viaje que él o ella no ha hecho nunca, o aproximándole a un tema que quizá nadie en el pasado ha considerado estudiar. Esta es realmente la situación en el caso del nuevo libro de Brian Kennedy y Elizabeth Guo Chinese Martial Arts Training Manuals: A Historical Survey.

Para empezar con esta revisión, puede ser bueno para este revisor confesar que padece un caso avanzado de bibliomanía. Parafraseando a Will Rogers, nunca ha encontrado un libro que no le guste, al menos hasta cierto 